\title{
Methods for quantifying follicular numbers within the mouse ovary
}

\author{
M Myers*, K L Britt ${ }^{1,2, *}$, N G M Wreford, F J P Ebling ${ }^{3}$ and J B Kerr \\ Departments of Anatomy and Cell Biology and ${ }^{1}$ Biochemistry and Molecular Biology, School of Biomedical \\ Sciences, Monash University, Clayton, VIC, Australia, ${ }^{2}$ Prince Henry's Institute of Medical Research, Clayton, VIC, \\ Australia and ${ }^{3}$ School of Biomedical Sciences, Queen's Medical Centre, University of Nottingham, Nottingham, \\ UK \\ Correspondence should be addressed to J Kerr, Department of Anatomy and Cell Biology, School of Biomedical Sciences, \\ Building 13C Faculty of Medicine, Monash University, VIC 3800, Australia; Email: jeff.kerr@med.monash.edu.au
}

*M Myers and KL Britt contributed equally to this work

\begin{abstract}
Accurate estimation of the number of ovarian follicles at various stages of development is an important indicator of the process of folliculogenesis in relation to the endocrine signals and paracrine/autocrine mechanisms that control the growth and maturation of the oocytes and their supporting follicular cells. There are 10-fold or greater differences in follicular numbers per ovary at similar ages and/or strains reported in earlier studies using various methods, leading to difficulties with interpretation of ovarian function in control vs experimental conditions. This study describes unbiased, assumption-free stereological methods for quantification of early and growing follicular numbers in the mouse ovary. A fractionator approach was used to sample a defined fraction of histological sections of adult wild-type ovaries. Primordial and primary follicles were counted independently with the optical and physical disector methods. The fractionator/disector methods, which are independent of follicular size or shape, gave estimations of $1930 \pm 286$ (S.E.M.) and $2227 \pm 101$ primordial follicles, and $137 \pm 25$ and $265 \pm 32$ primary follicles per ovary at 70 and 100 days of age respectively. From exact counts on serial sections, secondary and later follicular numbers at 100 days of age were estimated at 135 per ovary. Remnants of zona pellucidae (a marker of previous follicular atresia) were estimated using a fractionator/physical disector approach and were approximately $\mathbf{5 0 0}$ per ovary. The application of the quantitative methods described will facilitate an improved understanding of follicular dynamics and the factors that mediate their growth and maturation and allow for a better comparison between different studies.

Reproduction (2004) 127 569-580
\end{abstract}

\section{Introduction}

The coordinated development of follicles within the ovary is under the tight control of both hormones and growth factors (Findlay \& Drummond 1996, McGee \& Hsueh 2000, Richards 2001, Fortune 2003). Their appropriate stimulation of follicular growth and the accompanying developmental arrest of most follicles leads to the cyclical nature of mammalian female reproduction, and ultimately the release of viable oocytes. The complement of developing follicles within the ovary originates from and is dependent on the immature non-growing stock of primordial follicles. Coordinated entry of these follicles into the growth phase controls the rate at which the follicular reserve is depleted.

The study of follicular numbers can provide important information about the function of the ovary, in particular the relationship between folliculogenesis and the factors that regulate it. This may be important, for example in determining the relative roles of gonadotrophic and steroid hormones and local intraovarian growth factors in regulating the survival and maturation of follicles at any stage of their development. For decades rodent species have been used as models for reproductive function in women and the functional morphology of the mouse ovary is becoming increasingly important as a plethora of genetic modifications (knock-out (KO) and knock-in gene mutations) are available that alter the process of folliculogenesis. Although there have been many studies of folliculogenesis in both healthy and diseased ovaries the number of follicles per ovary is not routinely determined. In a selection of studies of the mouse ovary where follicular numbers have been counted, a large variation (up to 10-fold) exists between the numbers of early follicles 
reported (reviewed by Tilly 2003). With a valid and reliable counting scheme, the mouse ovary has the potential to be a key tool for monitoring the effects of multiple factors on primordial follicular endowment and maturation.

'Stereology is a uniform set of simple and efficient methods for quantification configured to provide reliable data from histologic sections' (Gundersen et al. 1988). The fractionator technique (Gundersen 1986) can be applied to determine follicular numbers per ovary. In this method a systematically sampled fraction of the ovary is exhaustively counted with respect to follicles. The number of follicles counted in this way is referred to as the raw count $\mathrm{Q}^{-}$- an abbreviation of German 'Querschnitte' for the profiles related to histological cross-sections, introduced by Sterio (1984). When the raw count is multiplied by the reciprocal of the sampling fractions it gives an unbiased estimate of follicular numbers per ovary. Sampling the ovary using the fractionator method avoids the problem of accounting for changes in organ volume (shrinkage or swelling) during fixation, dehydration and embedding. Typically the sampling fractions are chosen to allow counting of a total of 100-200 follicles in the tissue samples. Subject to follicles being independently sampled this gives a coefficient of error for the estimate below $10 \%$ (Gundersen 1986, Gundersen \& Jensen 1987, Michel \& Cruz-Orive 1988, Braendgaard et al. 1990). The particles on the sampled sections are counted using the optical or physical disector technique (Wreford 1995). These stereological methods have been previously applied to estimate neuron numbers in the central nervous system (Braendgaard et al. 1990, West et al. 1991, Ishiyama et al. 2001, Galvin \& Oorschot 2003), nephron and glomerular numbers in the kidney (Bertram 1995, 2001) and germ cell numbers in the testis (Wreford 1995, Kumar et al. 2001). The fractionator/disector method has previously been used in the primate ovary (Miller et al. 1997) and recently in the neonatal mouse ovary (Sonne-Hansen et al. 2003). The use of stereology in the adult mouse ovary has been limited and the methodological details sparse.

This study provides information about stereological approaches that can be applied to the mouse ovary and can be extrapolated to ovaries of other species. We define benchmark protocols for estimating the number of primordial and primary follicles in the ovary using either glycolmethacrylate resin- or paraffin-embedded ovarian samples. The number of post-primary maturing and differentiated follicles was determined using exact counts over all sections. These follicles cannot be assessed reliably using sampling techniques because in comparison with primordial and primary follicles, they are rare. We propose that our study provides baseline data and a protocol for future investigations.

\section{Materials and Methods}

\section{Animals}

Wild-type female C57BL/6/128SvEv mice, $n=7$, (Department of Anatomy and Cell Biology) at 100 days of age (25 g) and wild-type female J129/C57B6 mice, $n=5$, (Prince Henry's Institute of Medical Research) at 70 days of age $(22 \mathrm{~g})$ were kept on a $12 \mathrm{~h}$ light: $12 \mathrm{~h}$ darkness regimen under specific pathogen-free conditions with mouse chow freely available. These genetically similar strains were selected for stereological analysis since they form the basis for two separate breeding colonies used to generate mice with respective null mutations (KO models) of the genes for follicle-stimulating hormone- $\beta$ ( $\mathrm{FSH} \beta-\mathrm{KO})$ and aromatase enzyme (ArKO). All animal procedures were approved by the Animal Ethics Committee at Monash University and were carried out in accordance with the 'Australian Code of Practice for the Care and Use of Animals for Scientific Purposes'.

\section{Tissue collection and processing}

Daily vaginal smears were taken and stained using Quick Dip stain (Fronine, Riverstone, NSW, Australia) to ascertain cyclicity and all ovaries were collected in dioestrus. Left and right ovaries were randomly assigned to be fixed in Bouin's fluid and then processed through graded alcohols into either glycolmethacrylate resin (Technovit 7100; Heraeus Kulzer $\mathrm{GmbH}$, Wehrheim, Germany) or paraffin wax. Glycolmethacrylate resin-embedded ovaries (one per animal) were serially sectioned at $20 \mu \mathrm{m}$, stained with periodic acid-Schiff (PAS) and counterstained with haematoxylin. Paraffin-embedded ovaries (one per animal) were serially sectioned at $3 \mu \mathrm{m}$ and stained with a modified Masson trichrome stain.

\section{Morphological classification of follicles}

Follicles were classified as primordial if they contained an oocyte surrounded by a partial or complete layer of squamous granulosa cells. Primary follicles showed a single layer of cuboidal granulosa cells. Occasional follicles

\footnotetext{
Figure 1 Follicular classification. The classification of follicular stages used for analysis. (a) Primordial follicles were defined as an oocyte (o) surrounded by a layer of squamous (flattened) granulosa cells (arrow). Follicles which possessed predominantly cuboidal granulosa cells (arrowhead) with some squamous granulosa cells were classified as primary. Bar $=20 \mu \mathrm{m}$. (b) Primary follicles possessed an oocyte surrounded by a single layer of cuboidal granulosa cells (arrow). Bar $=20 \mu \mathrm{m}$. (c) Secondary follicles were surrounded by more than one layer of cuboidal granulosa cells, with no visible antrum. Bar $=50 \mu \mathrm{m}$. (d) Early antral follicles have emerging antral spaces (arrow), whilst antral follicles (e) possessed a clearly defined antral space (arrow); bars $=100 \mu \mathrm{m}$. $(\mathrm{f})$ Preovulatory follicles were the largest of the follicular types and possessed a defined cumulus granulosa cell layer (arrowhead). Bar $=200 \mu \mathrm{m}$. (g) ZP of healthy follicles (arrow) and ZPRs representing end-stage atretic follicles (arrowhead). Bar $=100 \mu \mathrm{m}$. (h) High magnification of ZPR (arrowhead), which is easily distinguished from neighbouring blood vessels (arrow). Bar $=100 \mu \mathrm{m}$.
} 

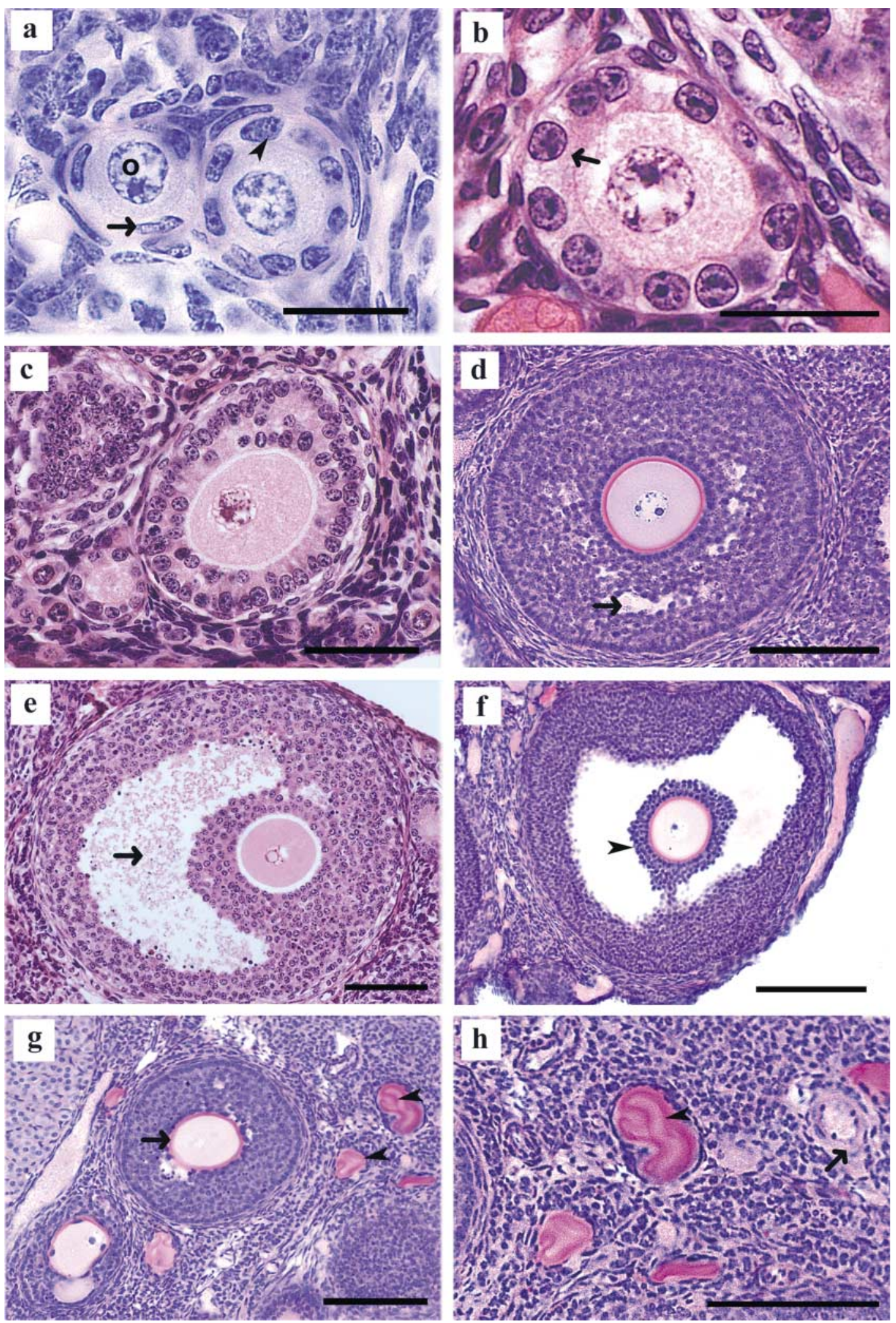
were observed as intermediate between primordial and primary and had both cuboidal and squamous granulosa cells. If cuboidal cells predominated follicles were classified as the primary type. Many previous investigations classify mouse follicles according to Pedersen \& Peters' (1968) classification scheme, which determined class based on granulosa cell number rather than follicle and granulosa cell appearance. Although such a classification is inherently biased by the section thickness, the classification used in this study approximates to types 1 to 3b described by Pedersen \& Peters (1968).

Follicles were classed as secondary if they possessed more than one layer of granulosa cells with no visible antrum. Early antral follicles possessed generally only one or two small areas of follicular fluid (antrum) whilst antral follicles possessed a single large antral space (Fig. 1). Preovulatory follicles had a rim of cumulus cells surrounding the oocyte. Following atresia, the zona pellucida (ZP)
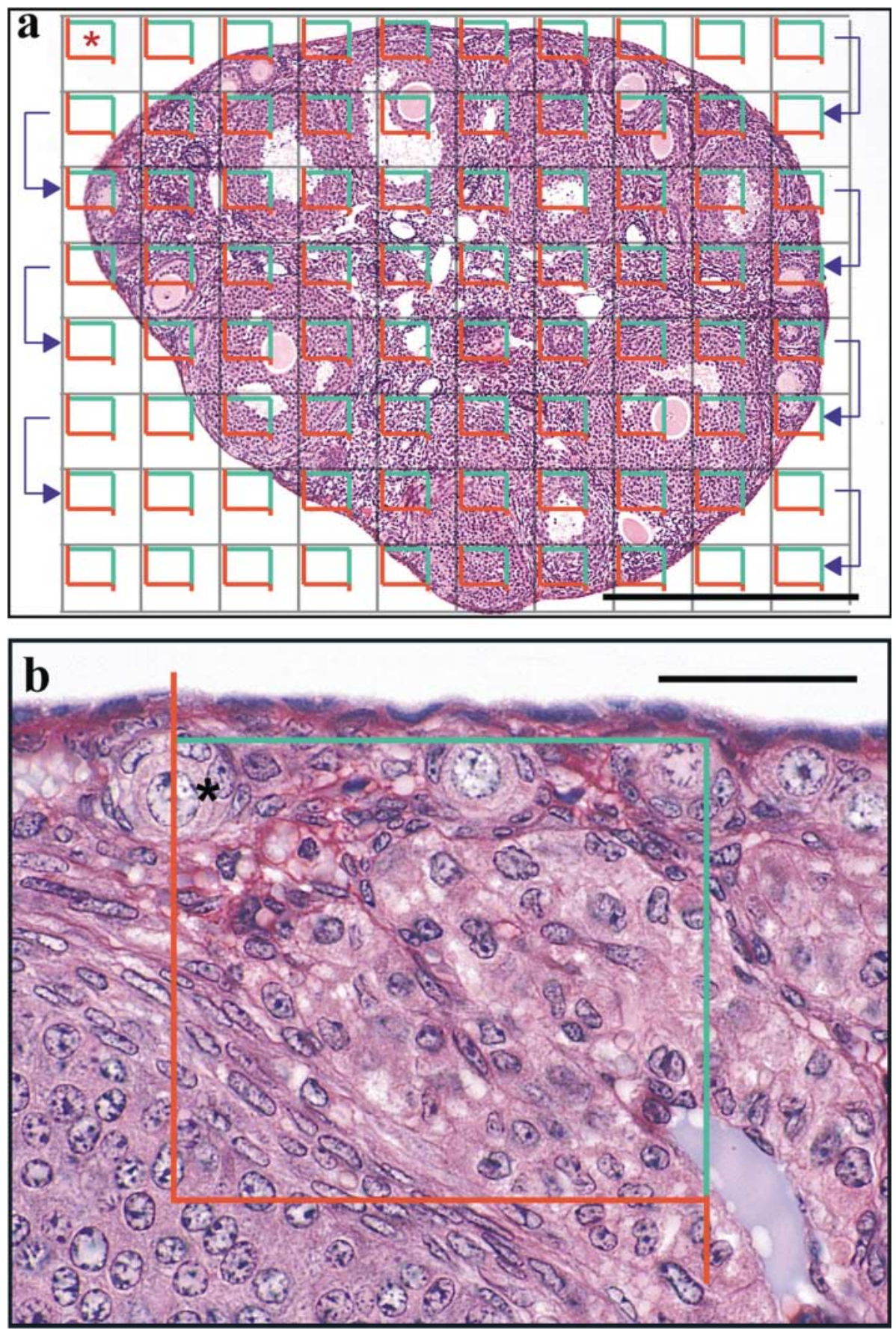

Figure 2 Sampling the ovaries to estimate follicles per ovary. Representation of sampling schemes (not to scale) used to sample a proportion of the ovary for the estimation of small follicular numbers per ovary. (a) The ovarian section is traced around the tissue boundaries with the computerised software and a sampling grid (dashed lines) is superimposed over the section. Each square of the sampling grid represents a sampled area measuring $6400 \mu \mathrm{m}^{2}$ or

$22500 \mu \mathrm{m}^{2}$ for the optical and physical disectors respectively. A counting frame (green- and red-sided boxes) is then used to sample a predetermined area within each square of the sampling grid beginning at *. The counting frame is systematically moved along the $\mathrm{X}$ - and $\mathrm{Y}$-axis to sample the ovarian section in the direction indicated by the arrows. Bar $=0.5 \mathrm{~mm}$. (b) The frame itself contains inclusion (green) and exclusion (red) boundaries. Oocyte nuclei are counted if (i) they appear within the unbiased counting frame and are (ii) not intersected by exclusion boundaries and (iii) appear in sharp focus in the $10 \mu \mathrm{m}$ counting depth sampled with the optical disector or do not appear in the look up section (physical disector). For example, the primordial follicle $(*)$ intersected by the exclusion boundary cannot be included as the oocyte nucleus is touching the red exclusion line. The other two primordial follicles to the right can be included as they satisfy the counting criteria by falling within the counting frame and touching only the green inclusion boundary. Bar $=40 \mu \mathrm{m}$. 
remnants (ZPRs) were readily recognised as structures staining brightly with PAS in thick methacrylate sections.

\section{Determination of primordial and primary follicular numbers in the ovary}

The heterogeneous nature of the ovary and the large size differences that exist between primordial and primary and later follicles necessitated the use of different methods to determine their respective numbers. The numbers of primordial and primary follicles were determined using a fractionator/optical disector design applied to thick methacrylate sections, or a fractionator/physical disector design applied to paraffin sections. Pilot studies were conducted to determine the most appropriate sampling (one that is both time efficient and allows approximately 100-200 oocytes to be counted) fractions for both optical and physical disector designs.

\section{Quantification of primordial and primary follicles: optical disector}

A fractionator/optical disector design (Gundersen et al. 1988, Wreford 1995) was used to estimate these follicular numbers in the ovaries obtained from C57BL/6/128SvEv mice at 100 days. Follicular counts were made using a $\times 100$ oil immersion objective with a high numerical aperture $\left(\mathrm{N}_{\mathrm{A}}=1.4\right)$ on an Olympus BX51 microscope equipped with an Autoscan stage (Autoscan Systems Pty Ltd, Melbourne, Victoria, Australia). Sections were sampled and follicles were counted using the CASTGRID specialised stereological system (CAST 2002; Olympus, Albertslund, Denmark) to generate the counting frame.

With the fractionator/optical design three levels of sampling were used and sampling designs were all systematic uniform from a random start (Gundersen \& Jensen 1987, Wreford, 1995). For the first level of sampling every 3rd section was chosen from a random start (sampling fraction $1(f 1)=1 / 3$ ) and its outline was traced using the CASTGRID program. A counting frame (measuring $2547 \mu^{2}$ ) was superimposed over the section (Fig. 2a and $b$ ) and was then shifted progressively along the $X$ - and Y-axis (in $80 \mu \mathrm{m}$ steps) in a sampling grid that subdivided the sections into $6400 \mu \mathrm{m}^{2}$ squares (sampling fraction 2 $(\mathfrak{f} 2)=2547 / 6400)$. To avoid artefacts at the surface of sections, the top of the section was brought into focus. The first $3 \mu \mathrm{m}$ of section depth was used as a guard area (noncounting), to avoid surface cutting irregularities that may bias the follicular count (Fig. 3a). For the 3rd level of sampling, the next $10 \mu \mathrm{m}$ of the $20 \mu \mathrm{m}$ section thickness was optically sectioned and oocytes were counted as they came into focus. Oocyte nuclear number was equated to follicular number. Nuclei were counted if they came into sharp focus between 3 and $13 \mu \mathrm{m}$ (sampling fraction 3 $(f 3)=10 / 20$ ) and were wholly or partially within the unbiased counting frame but not crossing the exclusion boundaries (Gundersen 1986) as shown in Fig. 2b. Raw counts $\left(\mathrm{Q}^{-}\right)$of follicular number were multiplied by the reciprocals of the sampling fractions to estimate the total number of follicles per ovary. Raw counts $\left(\mathrm{Q}^{-}\right)$using the optical disector ranged between 113 and 164 and 10 and 21 for primordial and primary follicles respectively.

Follicles per ovary (for both primordial and primary follicles $)=\mathrm{Q}_{(\text {follicle })}^{-} \cdot(1 / \mathrm{f} 1) \cdot(1 / \mathrm{f} 2) \cdot(1 / \mathrm{f} 3), \quad$ and substituting the data above in the reciprocal fractions...= $\mathrm{Q}_{(\text {follicle })}^{-} \cdot(3 / 1) \cdot(6400 / 2547) \cdot(20 / 10)$.

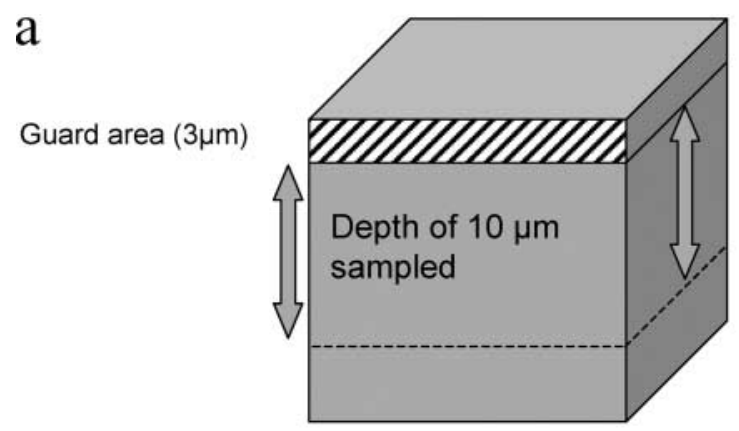

\section{Optical disector}
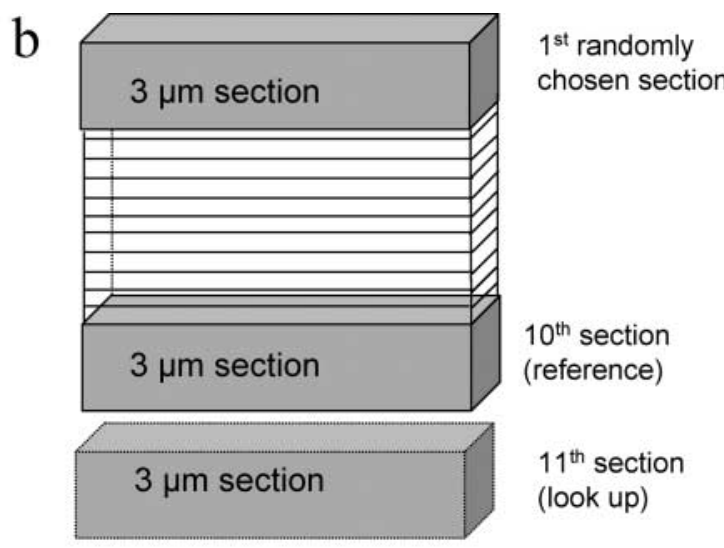

\section{Physical disector}

Figure 3 Dissecting the ovary using the optical or physical disector probes. For counting purposes the top and bottom of the sections used for optical dissecting (a) are ignored as they are prone to cutting artefacts which can bias estimates. Follicles are counted as they come into focus as the scan proceeds through the depth of the section. (b) The physical disector used a pair of separate physical sections. Every 10th and 11th section was chosen and a single focal plane was aligned on both sections. Follicles were counted if they appeared in one (reference) section but not the other ('look up') section. 


\section{Quantification of primordial and primary follicles: physical disector}

A fractionator/physical disector design (Braendgaard \& Gundersen 1986, Miller et al. 1997) was used to estimate these follicular numbers in the ovaries obtained from J129/C57B6 mice at 70 days. Follicular counts were made using a $\times 40$ oil immersion objective $\left(\mathrm{N}_{\mathrm{A}}=1.0\right)$ on an Olympus BX51 microscope. Sections were sampled and follicles were counted using the CASTGRID system to generate the counting frame (v2.1.4; Olympus).

Using the fractionator/physical design two levels of sampling were used and again, sampling was systematically uniform from a random start (Gundersen \& Jensen 1987, Wreford 1995). For the first level of sampling every 10 th and 11th section was sampled. Typically, in the physical disector design, one of these sections is designated the reference section and the other the 'look up' section (Fig. 3b). Subsequently, the analysis is performed in both directions with the reference section also becoming the 'look up' section. This doubles the first sampling fraction from $1 / 10$ th to $1 / 5$ th (sampling fraction $1(f 1)=1 / 5)$. For the second level of sampling tissue sections were traced (Fig. 2a) to define tissue boundaries and then sections were sampled on a $150 \times 150 \mu \mathrm{m}$ $\left(22500 \mu \mathrm{m}^{2}\right)$ sampling grid using an unbiased counting frame measuring $6749 \mu \mathrm{m}^{2}$ (sampling fraction 2: (f2) $=6749 / 22500$ ) for primordial and $16873 \mu \mathrm{m}^{2}$ for primary follicles (sampling fraction 2: (f2) $=16873 / 22500$ ). Separate counting frames were used to count primordial and primary follicles to try and ensure that 100-200 primordial follicles were counted. The CASTGRID software was used to facilitate matching of fields between the reference section and the consecutive 'look up' section. Oocyte nuclear number was equated to follicular number. Oocyte nuclei were counted if (i) they appeared within the unbiased counting frame applied to the reference section, (ii) were not intersected by exclusion boundaries

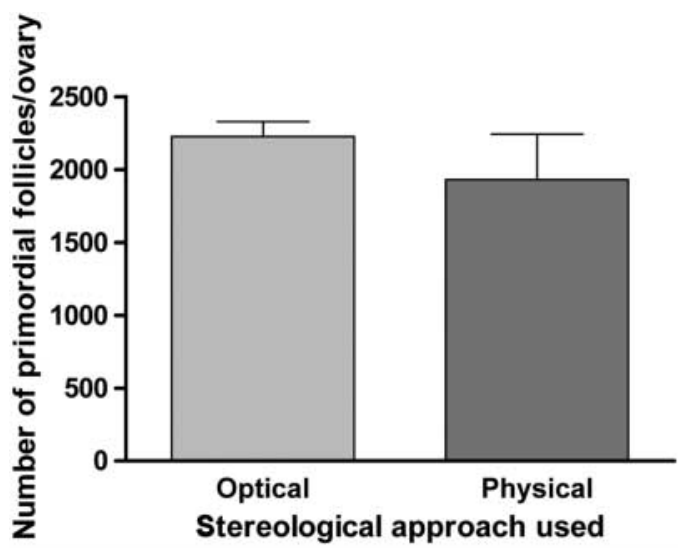

Figure 4 Primordial follicular numbers calculated using optical and physical disectors. The numbers of primordial follicles per ovary in adult mice using either the optical (100-day-old animals) or physical disector (70-day-old animals) in combination with the fractionator design. Results are presented as means \pm S.E.M. $(n=5-7)$.
(Gundersen 1986) and (iii) did not appear in the 'look up' section.

Raw counts $\left(\mathrm{Q}^{-}\right)$using the physical disector ranged between 62 and 163 and 13 and 33 for primordial and primary follicles respectively. Primordial follicular number per ovary $=\mathrm{Q}_{(\text {primordial) }}^{-} \cdot(1 / \mathrm{f} 1) \cdot(1 / \mathrm{f} 2)$, and substituting the data above in the reciprocal fractions...= $\mathrm{Q}_{\text {(primordial) }}^{-} \cdot(5 / 1) \cdot(22500 / 6749)$. Primary follicular number per ovary $=Q_{\text {(primary) }}^{-} \cdot(1 / \mathrm{f} 1) \cdot(1 / \mathrm{f} 2)$, and substituting the data above in the reciprocal fractions... = $\mathrm{Q}_{\text {(primary) }}^{-}(5 / 1) \cdot(22$ 500/16 873).

\section{Quantification of secondary, antral and atretic follicles}

More advanced follicles (secondary type and beyond) were estimated by exact counts determined from digital images of consecutive $20 \mu \mathrm{m}$ glycolmethacrylate sections encompassing whole cross-sections of the ovary. Again oocyte nuclear number was equated to follicular number. ZPRs were similarly counted on digital images but this time using the fractionator/physical disector type approach. Every 10th and 11th section pair was sampled using the physical disector design described above and counting was performed in both directions (sampling fraction $1(\mathrm{f} 1)=1 / 5)$. ZPR number per ovary $=\mathrm{Q}_{(\mathrm{ZPR})}^{-} \cdot(1 / \mathrm{f} 1)$, and substituting the data above in the reciprocal fraction... $=\mathrm{Q}_{(\mathrm{ZPR})}^{-} \cdot(5 / 1)$

\section{Presentation of data}

All data are expressed as means \pm S.E.M.

\section{Results}

Two independent methods, the optical and physical disectors in combination with the fractionator sampling

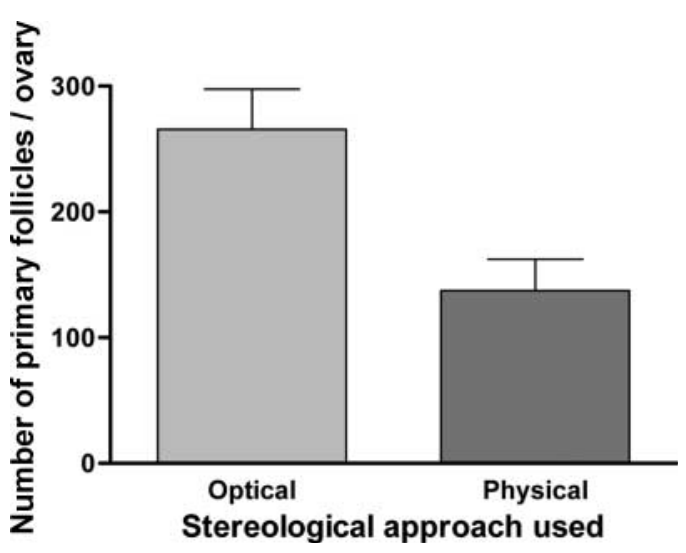

Figure 5 Primary follicular numbers calculated using the optical and physical disectors. The numbers of primary follicles per ovary in adult mice using either the optical (100-day-old animals) or physical disector (70-day-old animals) in combination with the fractionator design. Results are presented as means \pm S.E.M. $(n=5-7)$. 
technique, were used in the current study to assess the numbers of primordial and primary follicles.

\section{Primordial follicles (Fig. 4)}

The number of primordial follicles per ovary in C57BL/6/128SvEv mice at 100 days using the optical disector was $2227 \pm 101$. The number of primordial follicles per ovary in J129/C57B6 mice at 70 days using the physical disector was $1930 \pm 286$.

\section{Primary follicles (Fig. 5)}

The number of primary follicles per ovary determined at 100 days of age using the optical disector was $265 \pm 32$ and $137 \pm 25$ at 70 days of age using the physical disector.

\section{Secondary, antral and atretic follicles (Fig. 6)}

The numbers of secondary and more mature follicles determined from exact counts (on consecutive $20 \mu \mathrm{m} \mathrm{sec}-$ tions) in 100-day-old mice were divided into histologically defined subclasses. There were $79 \pm 5.6$ secondary follicles, $40 \pm 4.8$ early antral follicles, $15.6 \pm 2.3$ antral follicles, and $2.6 \pm 0.6$ preovulatory follicles. Numbers of ZPRs were determined by the physical disector approach as an indicator of follicles which had earlier undergone atresia (Peters 1969, Elvin et al. 1999). The number of ZPRs was $512 \pm 29$. Total follicle counts per ovary (primordial, primary, secondary, early antral, antral and preovulatory) estimated in the methacrylate resin at 100 days were $2629 \pm 139$.

\section{Discussion}

We have described two independent methods that incorporate design-based stereological approaches to determine

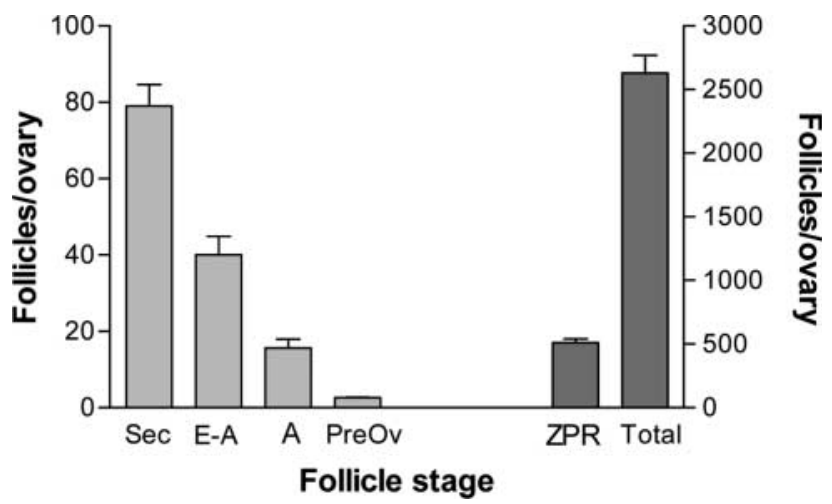

Figure 6 Secondary, antral and atretic follicular numbers calculated from raw counts. The total number of follicles (secondary, early antral, antral and preovulatory) in 100-day-old animals were estimated by exact counts applied to digital images of consecutive sections. ZPRs were calculated using a fractionator/physical disector approach. $\mathrm{Sec}=$ secondary; $\mathrm{E}-\mathrm{A}=$ early antral; $\mathrm{A}=$ antral; PreOv $=$ preovulatory; Total $=$ all follicular classes in the ovary. Results are presented as means \pm S.E.M. $(n=7)$. the number of follicles per ovary. These data provide a basis for quantifying the supply and attrition of follicles in the normal ovary and the anomalous behaviour of ovaries in cases of ovarian disorders and infertility.

We believe the variation in follicular number reported by others (Figs 7 and 8) reflects inherent biases in the counting techniques used. Previous studies used twodimensional analysis with fractionator-type designs for ovaries embedded in paraffin and serially sectioned at $3-8 \mu \mathrm{m}$. These other studies used a proportion of the cut sections (i.e. every 2 nd up to every 10 th section). However, it was not always clear how these sampling fractions had been incorporated into the calculations relating raw counts to the actual estimates of follicular number per ovary. This can be highlighted by the studies of Benedict et al. (2000), Rucker et al. (2000) and Tomic et al. (2002) in which all classes of follicles were counted in every 10th section of the ovary. In the first study, raw follicular counts were multiplied by 10 (i.e. the sampling fraction with respect to every 10th section being counted); the second study reported no correction factors; in the third study, raw counts were further corrected by a factor equal to the $8 \mu \mathrm{m}$ section thickness giving a combined correction factor of multiplication by 80 . The justification for the latter correction is obscure. Classically in the methods described by Floderus (1944) and by Abercrombie (1946), counts are corrected for section thickness and particle diameter but application of these factors in fractionator designs is not appropriate and will probably lead to an overestimation of follicles (Tilly 2003). In the reports of Rucker et al. (2000) and Tomic et al. (2002) for 90-dayold mouse ovaries, the numbers of primordial follicles per ovary are similar (10000-11000) as are the total follicles per ovary (16000-18000) despite the former study using no correction factors whereas the latter study used a correction factor of multiplying raw counts by 80 . Smith et al. (1991) studied 50- to 70-day-old mice, and reported only 371 primordial follicles per ovary but sampling fractions were not specified. These results do not appear to have been corrected for the sampling fraction. Presumably this low number reflects an incorrect calculation from raw to estimated follicles per ovary. Using every 10th paraffin section of thickness $7 \mu \mathrm{m}$ (with no correction factor) Halpin et al. (1986) reported primordial follicular numbers at 60, 90 and 120 days of age to be 2030, 2220 and 1890 per ovary respectively, in broad agreement with our estimates using unbiased stereology.

Using the optical disector technique applied to ovaries from 100-day-old animals we estimated the primordial follicular number to be approximately 2200 per ovary. Applying the physical disector technique to ovaries from 70-day-old animals from a related strain, we estimated the primordial follicular number to be approximately 1930 per ovary. Despite having used two different but genetically related strains of mice (both Black 6 strains), different embedding media (glycolmethacrylate resin or paraffin) and two counting methods, the number of primordial 


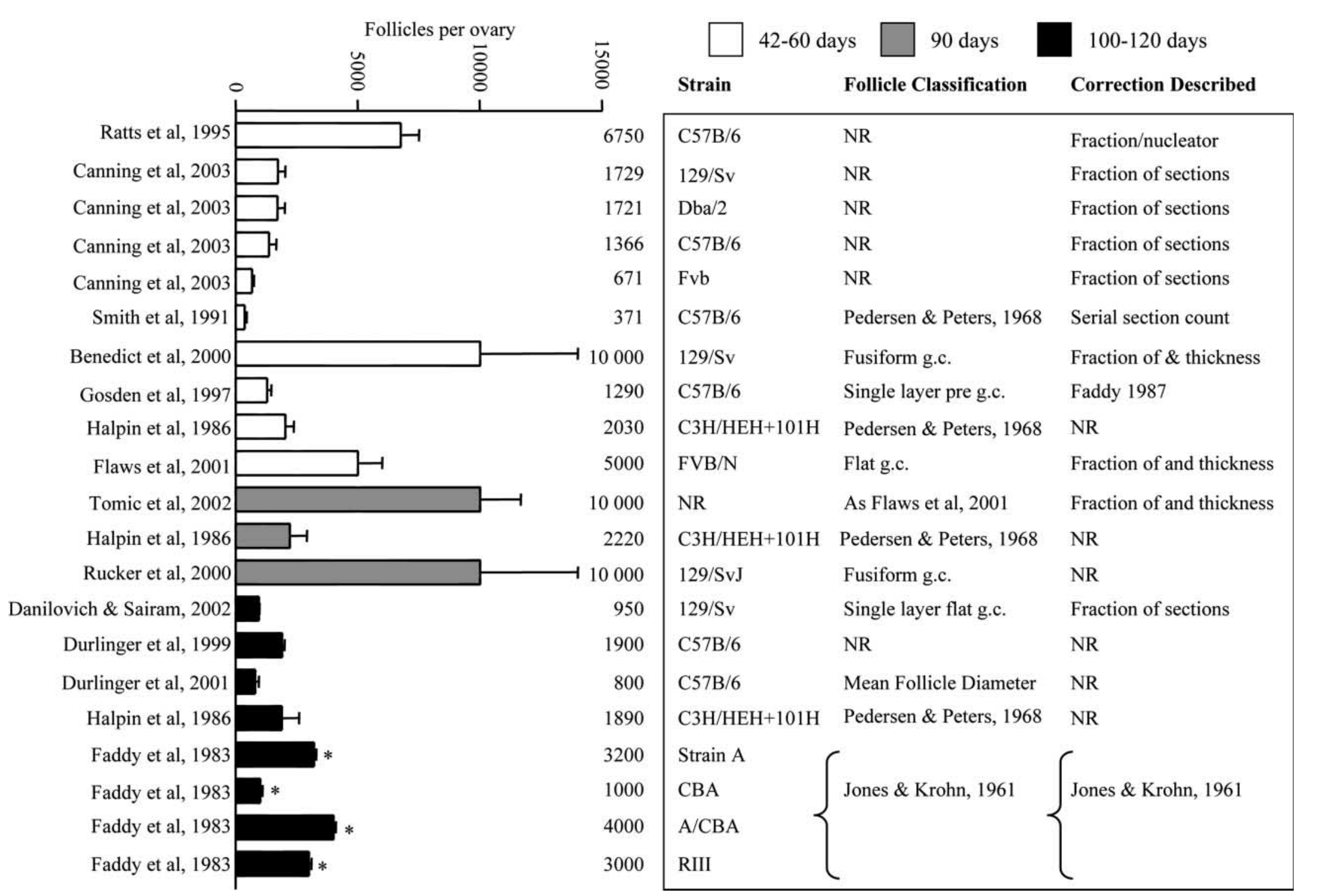

Figure 7 Primordial follicular numbers from previous investigators. Follicular numbers from previous investigations are aligned with the mouse species analysed, follicular classification used and sampling corrections reported. The follicular classification allows the definition of primordial follicles. The corrections described are those reported by authors for estimating follicles per ovary from raw follicle counts. All follicular numbers are estimates of published graphical representations except for those labelled with an asterisk, where numerical values are reported. g.c. $=$ granulosa cells; $\mathrm{NR}=$ not reported in the study. Follicular counts are represented as means \pm S.E.M. 


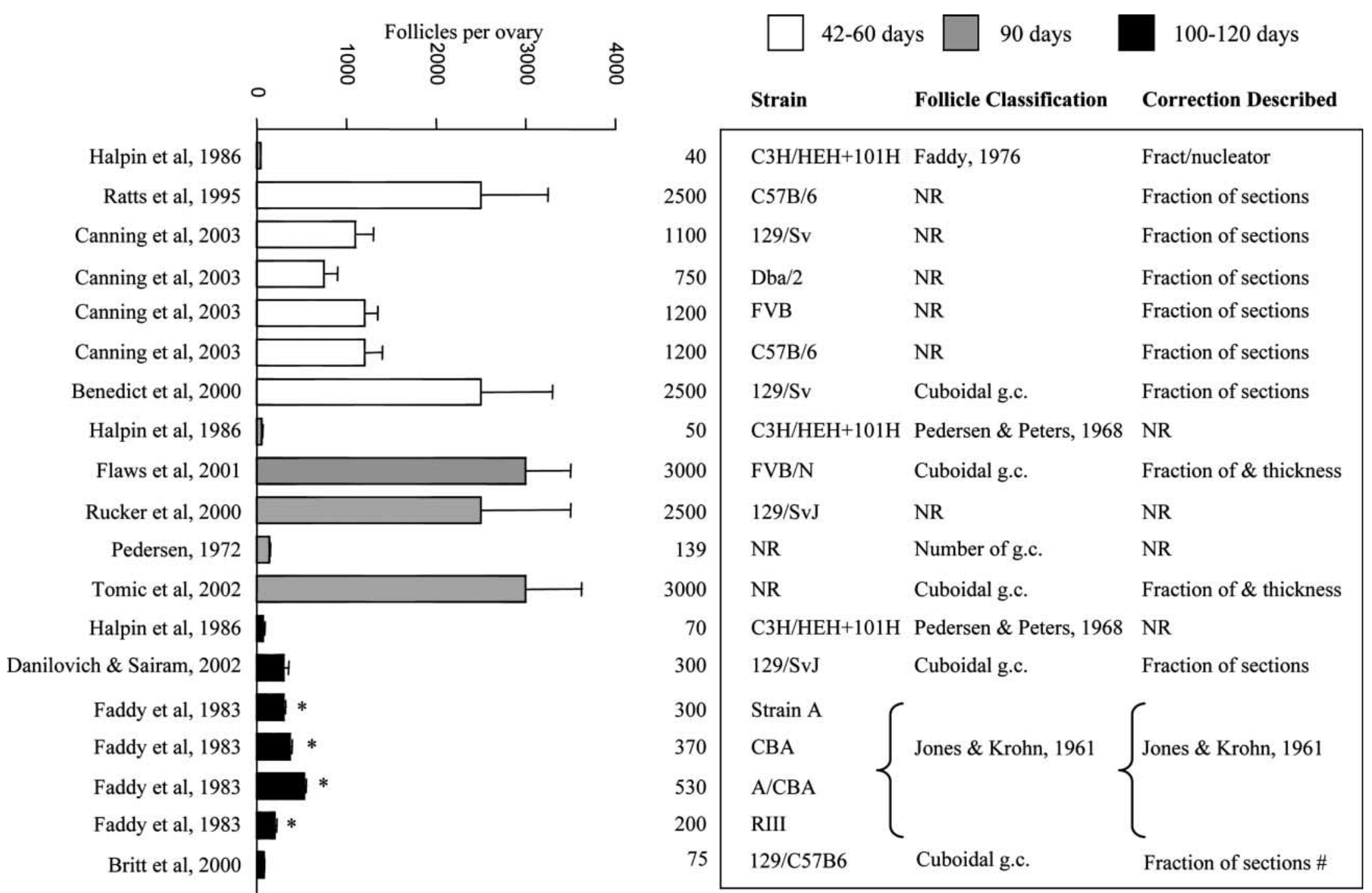

Figure 8 Primary follicular numbers from previous investigators. Follicular numbers from previous investigations are aligned with the mouse species analysed, follicular classification used and sampling corrections reported. The follicular classification allows the definition of primary follicles. The corrections described are those reported by authors for estimating follicles/ovary from raw follicular counts. All follicular numbers are estimates of published graphical representations except for those labelled with an asterisk, where numerical values are reported. g.c. $=$ granulosa cells; NR = not reported in the study; \#Abercrombie (1946) and Floderus (1944) correction applied. Follicular counts are represented as means \pm S.E.M. 
follicles per ovary is similar in the current study. Both disector methods offer assumption-free estimates of follicular number, although the optical disector method has the advantage of efficiency (time) in application compared with the physical disector.

Approximately 135-265 primary follicles per ovary were found using the physical and optical disector respectively. The scarcity of primary follicles and possible differences between animal strains means that raw counts did not fall within the 100-200 range predicted to give a coefficient of error below $10 \%$. More rigorous studies with increased sampling fractions would rectify this if accurate numbers were required in an experimental context. Primary follicular numbers determined by others (Fig. 8) range from 40 to 3000. As indicated above, the correction factors (including calculations for sampling) vary widely and lead to overestimation (Ratts et al. 1995, Benedict et al. 2000, Tomic et al. 2002).

Early antral and established antral follicles proper (approximately 40 and 15 per ovary respectively) were subclassified because in many mouse $\mathrm{KO}$ models it is within the antral follicular stage that follicular arrest often occurs (ArKO, Britt et al. (2000); hypogonadal, Halpin et al. (1986); luteinising hormone receptor $\mathrm{KO}$, Lei et al. (2001); $\alpha \beta$ oestrogen receptor KO, Couse \& Korach (1999), Dupont et al. (2000); FSHß-KO, Kumar et al. (1997)). There were only $2.6 \pm 0.6$ preovulatory follicles per ovary in the current study. Exact counts of secondary and more mature follicles using serial photomicrographs were used as this is the only method that allows the stage of the follicle to be accurately ascertained (in contrast to single sections which give ambiguous classifications).

The ZP is a glycoprotein coat separating the oocyte from the surrounding granulosa cells and is first detected in primary follicles. As one of the last follicular components to degenerate during atresia, its persists after the demise of the oocyte and granulosa cells (Peters 1969, Inoue et al. 2000, Castrillon et al. 2003). ZPRs were counted to provide an indication of the number of those growing follicles that had developed a ZP, but had subsequently undergone atresia. This is only one of several possible classification systems that may be used to determine such numbers. Quantification of ZPRs allowed previously atretic follicles to be distinguished without the complication of assessing the degree of granulosa cell apoptosis (e.g. using pyknotic nuclei or cytochemical nick-end labelling of fragmented DNA). Apoptotic granulosa cells may not be present in all sections through a follicle and thus are not a reliable indicator of follicular atresia. We found approximately 510 ZPRs per ovary. Whilst our method neglects the estimation of follicular atresia occurring prior to ZP development (primordial and early primary follicles - for which there is no reliable method available) it may prove valuable when assessing mature follicular death in genetically altered animals.

Similar to the data on numbers of small follicles, the reported numbers of larger follicles show considerable variation. Secondary and maturing follicular numbers are difficult to ascertain from previous data, due to variation in classification schemes. Previous reports have used multiple schemes such as the Pederson \& Peters (1968) method, or follicular diameter, or cytological classification such as preantral, early, and established antral types. In particular if preantral (i.e. secondary) and antral follicles are grouped together (for ease of interpreting previous data) follicular numbers range from 57 between days 50 and 70 (Smith et al. 1991) to 6800 at day 53 (Benedict et al. 2000), with many variations in between (Pedersen, 1972, Ratts et al. 1995, Durlinger et al. 2001, Flaws et al. 2001, Danilovich \& Sairam 2002, Tomic et al. 2002, Canning et al. 2003). Our estimate for preantral and antral stages together is approximately 135 follicles per ovary based upon exact counts of serial sections where the oocyte nucleus is used as a defining feature, to avoid overestimation. Previous studies also used oocyte nuclei to define follicles but exact counts of all serial sections, to the best of our knowledge, have not been performed. Different classification schemes and selection of specific stages for analysis (most studies use only specific follicular stages, i.e. antral follicles) make a meaningful comparison of follicular numbers in each stage of development problematic. Whilst these classifications may not necessarily invalidate any single study's aim in attempting to define differences between control and treatment, as recently reviewed by Tilly (2003), they cannot be used to compare data across laboratories.

The disector method is preferred over two-dimensionalbased methods in that it ensures that follicular counts per ovary are not volume weighted (larger objects have a higher probability of being sampled, and the opposite for smaller objects) eliminating the necessity for correction factors (Bolender \& Charleston 1993, Dorph-Petersen et al. 2001). Experimentally altered ovaries may show changes of numbers and or dynamics within follicles. Follicles or oocytes may be retarded in their physical growth in size (Wang \& Greenwald 1993, Danilovich \& Sairam 2002, Balla et al. 2003, Yang et al. 2003) or show precocious enlargement (Wang \& Greenwald 1993, Carabatsos et al. 1998, Danilovich \& Sairam 2002, Castrillon et al. 2003) but these dysmorphic follicles are not necessarily accompanied by a change in their cytological classification. The disector method describes a probe that samples follicles with a uniform probability in a threedimensional space, irrespective of their size and shape (Gundersen et al. 1988).

For larger vertebrates an additional sampling fraction may need to be introduced, in that only a fraction of the ovary is taken such that a manageable number of blocks are left to be sectioned. Gundersen (1986) described methods for accurate estimations of cell or object number without the use of the entire organ and such methods have been used in the testis (Wreford 1995), kidney (Bertram 1995), central nervous system (Braendgaard et al. 
1990, Chadi et al. 2001), placenta (Mayhew et al. 1984) and liver (Marcos et al. 2003).

In conclusion, using either the physical or optical disector counting technique in combination with the fractionator sampling method, primordial and primary follicles can be accurately measured in either methacrylate resin or paraffin sections. Secondary and more mature follicular numbers were estimated using exact counts and provide a standard for further analysis. The application of these approaches for the study of folliculogenesis may contribute to a deeper understanding of the endocrine and paracrine factors that regulate ovarian function in normal and dysfunctional conditions.

\section{Acknowledgements}

This study was supported by a collaborative grant from AstraZeneca UK (F J P E and J B K), a grant from the NH\&MRC, Reg Key 983212 (Jock Findlay), and a Prince Henry's Institute of Medical Research Postgraduate Scholarship (K L B). The authors would like to thank Jock Findlay for critically reviewing the manuscript and lan Boundy, Robyn Kelly and Sue Connell for histological assistance.

\section{References}

Abercrombie M 1946 Estimation of nuclear population from microtome sections. Anatomical Record 94 239-247.

Balla A, Danilovich N, Yang Y \& Sairam MR 2003 Dynamics of ovarian development in the FORKO immature mouse: structural and functional implications for ovarian reserve. Biology of Reproduction 69 1281-1293.

Benedict JC, Lin TM, Loeffler IK, Peterson RE \& Flaws JA 2000 Physiological role of the aryl hydrocarbon receptor in mouse ovary development. Toxicological Sciences 56 382-388.

Bertram JF 1995 Analyzing renal glomeruli with the new stereology. International Review of Cytology 161 111-172.

Bertram JF 2001 Counting in the kidney. Kidney International 59 $792-796$.

Bolender RP \& Charleston JS 1993 Software for counting cells and estimating structural volumes with the optical disector and fractionator. Microscopy Research and Technique 25 314-324.

Braendgaard H, Evans SM, Howard CV \& Gundersen HJ 1990 The total number of neurons in the human neocortex unbiasedly estimated using optical disectors. Journal of Microscopy 157 285-304.

Britt KL, Drummond AE, Cox VA, Dyson M, Wreford NG, Jones ME, Simpson ER \& Findlay JK 2000 An age-related ovarian phenotype in mice with targeted disruption of the Cyp 19 (aromatase) gene. Endocrinology $1412614-2623$.

Canning J, Takai Y \& Tilly JL 2003 Evidence for genetic modifiers of ovarian follicular endowment and development from studies of five inbred mouse strains. Endocrinology 144 9-12.

Carabatsos MJ, Elvin J, Matzuk MM \& Albertini DF 1998 Characterization of oocyte and follicle development in growth differentiation factor-9-deficient mice. Developmental Biology 204 373-384.

Castrillon DH, Miao L, Kollipara R, Horner JW \& DePinho RA 2003 Suppression of ovarian follicle activation in mice by the transcription factor Foxo3a. Science 301 215-218.

Chadi G, Andrade MS, Leme RJ \& Gomide VC 2001 Experimental models of partial lesion of rat spinal cord to investigate neurodegeneration, glial activation, and behavior impairments. International Journal of Neuroscience 111 137-165.
Couse JF \& Korach KS 1999 Estrogen receptor null mice: what have we learned and where will they lead us? Endocrine Reviews 20 358-417.

Danilovich N \& Sairam MR 2002 Haploinsufficiency of the folliclestimulating hormone receptor accelerates oocyte loss inducing early reproductive senescence and biological aging in mice. Biology of Reproduction 67 361-369.

Dorph-Petersen KA, Nyengaard JR \& Gundersen HJ 2001 Tissue shrinkage and unbiased stereological estimation of particle number and size. Journal of Microscopy $204232-246$.

Dupont S, Krust A, Gansmuller A, Dierich A, Chambon P \& Mark M 2000 Effect of single and compound knockouts of estrogen receptors alpha (ERalpha) and beta (ERbeta) on mouse reproductive phenotypes. Development 127 4277-4291.

Durlinger AL, Kramer P, Karels B, de Jong FH, Uilenbroek JT, Grootegoed JA \& Themmen AP 1999 Control of primordial follicle recruitment by anti-Mullerian hormone in the mouse ovary. Endocrinology 140 5789-5796.

Durlinger AL, Gruijters MJ, Kramer P, Karels B, Kumar TR, Matzuk MM, Rose UM, de Jong FH, Uilenbroek JT, Grootegoed JA \& Themmen AP 2001 Anti-Mullerian hormone attenuates the effects of FSH on follicle development in the mouse ovary. Endocrinology 142 4891-4899.

Elvin JA, Yan C, Wang P, Nishimori K \& Matzuk MM 1999 Molecular characterization of the follicle defects in the growth differentiation factor 9-deficient ovary. Molecular Endocrinology 13 1018-1034.

Faddy MJ, Gosden RG \& Edwards RG 1983 Ovarian follicle dynamics in mice: a comparative study of three inbred strains and an F1 hybrid. Journal of Endocrinology 96 23-33.

Faddy MJ, Jones EC \& Edwards RG 1976 An analytical model for ovarian follicle dynamics. Journal of Experimental Zoology 197 $173-185$.

Faddy MJ, Teffer E \& Gosden RG 1987 The kinetics of pre-antral follicle development in ovaries of CBA/Ca mice during the first 14 weeks of life. Cell and Tissue Kinetics 20 551-560.

Findlay JK \& Drummond AE 1996 Control of follicular growth. In The Ovary: Regulation, Dysfunction and Treatment, pp 13-21. Eds M Filicori \& C Flamigni. Amsterdam: Elsevier Science.

Flaws JA, Hirshfield AN, Hewitt JA, Babus JK \& Furth PA 2001 Effect of bcl-2 on the primordial follicle endowment in the mouse ovary. Biology of Reproduction 64 1153-1159.

Floderus S 1944 Untersuchungen uber den Bau der menschlichen hypophse mit besondener Berucksichtigung der quantitativen mikromorphologischen Verhaltnisse. Acta Pathologica et Microbiologica Scandinavica 53 1-276.

Fortune JE 2003 The early stages of follicular development: activation of primordial follicles and growth of preantral follicles. Animal Reproduction Science 78 135-163.

Galvin KA \& Oorschot DE 2003 Continuous low-dose treatment with brain-derived neurotrophic factor or neurotrophin-3 protects striatal medium spiny neurons from mild neonatal hypoxia/ischemia: a stereological study. Neuroscience 118 1023-1032.

Gosden RG, Wade JC, Fraser HM, Sandow J \& Faddy MJ 1997 Impact of congenital or experimental hypogonadotrophism on the radiation sensitivity of the mouse ovary. Human Reproduction $\mathbf{1 2}$ 2483-2488.

Gundersen HJ 1986 Stereology of arbitrary particles. A review of unbiased number and size estimators and the presentation of some new ones, in memory of William $\mathrm{R}$ Thompson. Journal of Microscopy 143 3-45.

Gundersen HJ \& Jensen EB 1987 The efficiency of systematic sampling in stereology and its prediction. Journal of Microscopy $147229-263$.

Gundersen HJ, Bagger P, Bendtsen TF, Evans SM, Korbo L, Marcussen N, Moller A, Nielsen K, Nyengaard JR \& Pakkenberg B 1988 The new stereological tools: disector, fractionator, nucleator and point sampled intercepts and their use in pathological research and diagnosis. APMIS 96 857-881. 
Halpin DM, Jones A, Fink G \& Charlton HM 1986 Postnatal ovarian follicle development in hypogonadal (hpg) and normal mice and associated changes in the hypothalamic-pituitary-ovarian axis. Journal of Reproduction and Fertility 77 287-296.

Inoue S, Watanabe H, Saito H, Hiroi M \& Tonosaki A 2000 Elimination of atretic follicles from the mouse ovary: a TEM and immunohistochemical study in mice. Journal of Anatomy 196 $103-110$

Ishiyama A, Agena J, Lopez I \& Tang Y 2001 Unbiased stereological quantification of neurons in the human spiral ganglion. Neuroscience Letters 304 93-96.

Jones EC \& Krohn PL 1961 The relationships between age, numbers of oocytes and fertility in virgin and multiporous mice. Journal of Endocrinology 21 469-495.

Kumar TR, Wang Y, Lu N \& Matzuk MM 1997 Follicle stimulating hormone is required for ovarian follicle maturation but not male fertility. Nature Genetics 15 201-204.

Kumar TR, Varani S, Wreford NG, Telfer NM, de Kretser DM \& Matzuk MM 2001 Male reproductive phenotypes in double mutant mice lacking both FSHbeta and activin receptor IIA. Endocrinology $1423512-3518$.

Lei ZM, Mishra S, Zou W, Xu B, Foltz M, Li X \& Rao CV 2001 Targeted disruption of luteinizing hormone/human chorionic gonadotropin receptor gene. Molecular Endocrinology $\mathbf{1 5}$ $184-200$.

Marcos R, Rocha E, Henrique RM \& Monteiro RA 2003 A new approach to an unbiased estimate of the hepatic stellate cell index in the rat liver: an example in healthy conditions. Journal of Histochemistry and Cytochemistry 51 1101-1104.

Mayhew TM, Joy CF \& Haas JD 1984 Structure-function correlation in the human placenta: the morphometric diffusing capacity for oxygen at full term. Journal of Anatomy 139 691-708.

McGee EA \& Hsueh AJ 2000 Initial and cyclic recruitment of ovarian follicles. Endocrine Reviews 21 200-214.

Michel RP \& Cruz-Orive LM 1988 Application of the Cavalieri principle and vertical sections method to lung: estimation of volume and pleural surface area. Journal of Microscopy $\mathbf{1 5 0}$ 117-136.

Miller PB, Charleston JS, Battaglia DE, Klein NA \& Soules MR 1997 An accurate, simple method for unbiased determination of primordial follicle number in the primate ovary. Biology of Reproduction 56 909-915.

Pedersen T 1972 Follicle growth in the mouse ovary. In Oogenesis, pp 361-367. Eds J Biggers \& A Schuetz. London: University Park Press.

Pedersen T \& Peters H 1968 Proposal for a classification of oocytes and follicles in the mouse ovary. Journal of Reproduction and Fertility 17 555-557.
Peters H 1969 The development of the mouse ovary from birth to maturity. Acta Endocrinologica 62 98-116.

Ratts VS, Flaws JA, Kolp R, Sorenson CM \& Tilly JL 1995 Ablation of bcl-2 gene expression decreases the numbers of oocytes and primordial follicles established in the post-natal female mouse gonad. Endocrinology 136 3665-3668.

Richards JS 2001 Perspective: the ovarian follicle - a perspective in 2001. Endocrinology 142 2184-2193.

Rucker EB 3rd, Dierisseau P, Wagner KU, Garrett L, Wynshaw-Boris A, Flaws JA \& Hennighausen L $2000 \mathrm{Bcl}-\mathrm{x}$ and Bax regulate mouse primordial germ cell survival and apoptosis during embryogenesis. Molecular Endocrinology 14 1038-1052.

Smith BJ, Plowchalk DR, Sipes IG \& Mattison DR 1991 Comparison of random and serial sections in assessment of ovarian toxicity. Reproductive Toxicology 5 379-383.

Sonne-Hansen K, Nielsen M \& Byskov AG 2003 Oocyte number in newborn mice after prenatal octylphenol exposure. Reproductive Toxicology 17 59-66.

Sterio DC 1984 The unbiased estimation of number and sizes of arbitrary particles using the disector. Journal of Microscopy 134 $127-136$

Tilly JL 2003 Ovarian follicle counts - not as simple as 1, 2, 3. Reproductive Biology and Endocrinology 111-14.

Tomic D, Brodie SG, Deng C, Hickey RJ, Babus JK, Malkas LH \& Flaws JA 2002 Smad 3 may regulate follicular growth in the mouse ovary. Biology of Reproduction 66 917-923.

Wang XN \& Greenwald GS 1993 Hypophysectomy of the cyclic mouse I. Effects on folliculogenesis, oocyte growth, and follicle-stimulating hormone and human chorionic gonadotropin receptors. Biology of Reproduction 48 585-594.

West MJ, Slomianka L \& Gundersen HJ 1991 Unbiased stereological estimation of the total number of neurons in the subdivisions of the rat hippocampus using the optical fractionator. Anatomical Record 231 482-497.

Wreford NG 1995 Theory and practice of stereological techniques applied to the estimation of cell number and nuclear volume in the testis. Microscopy Research and Technique 32 423-436.

Yang Y, Balla A, Danilovich N \& Sairam MR 2003 Developmental and molecular aberrations associated with deterioration of oogenesis during complete or partial follicle-stimulating hormone receptor deficiency in mice. Biology of Reproduction 69 1294-1302.

Received 10 November 2003

First decision 1 January 2004

Accepted 27 February 2004 